\title{
REFLEXÕES PARA A IM PLEMENTAÇÃO DO MOVIMENTO CTS NO CONTEXTO EDUCACIONAL BRASILEIRO
}

\author{
D écio Auler* \\ Walter Antonio Bazzo**
}

\begin{abstract}
Resumo: Neste artigo, situamos, inicialmente, o surgimento histórico do movimento ciência, tecnologia e sociedade (CTS). Por se tratar de um movimento que emerge em contextos bastante distintos do nosso, num segundo momento discutimos aspectos a serem considerados na configuração de seus objetivos no contexto educacional brasileiro, apontando limitações e desafios que se colocam. D estacamos a nossa inexperiência democrática, relacionada com a trajetória histórica do país, como um dos obstáculos/desafios para colocar a tomada de decisões, em relação à ciência e à tecnologia, numa perspectiva mais democrática (mais atores sociais participando) e menos tecnocrática, aspecto central do CTS.
\end{abstract}

Unitermos: movimento CTS; contexto brasileiro; ensino de ciências

\begin{abstract}
In the present article we initially situate the historical appearance of the Science-Technology-Society movement (ST S). As it is a movement emerging in contexts which are quite different from ours, we then dis cuss aspects to be considered in the configuration of ST S's aims for the Brazilian educational context, identifying potential limitations and challenges. We also remark our lack of democratic experience, which is related to the countrys historical background, as one of the obstades for decision making regarding science and technology, in a more democratic (more social agents taking part of it) and less technocratic perspective, a core aspect for the ST S movement.
\end{abstract}

Keywords. CTS movement; brazilian context; science teaching

\section{Introdução}

A partir de meados do século XX, nos países capitalistas centrais, foi crescendo 0 sentimento de que o desenvolvimento científico, tecnológico e econômico não estava conduzindo, linear e automaticamente, ao desenvolvimento do bem-estar social. Após uma euforia inicial com os resultados do avanço científico e tecnológico, nas décadas de 1960 e 1970, a degradação ambiental, bem como a vinculação do desenvolvimento científico e tecnológico à guerra (as bombas atômicas, a guerra do V ietnã com seu napalm desfolhante) fizeram com que a ciência e a tecnologia ( $C \& T$ ) se tornassem alvo de um olhar mais crítico. Além disso, a publicação das obras A estrutura das revoluções científicas, pelo físico e historiador da ciência Thomas Kuhn, e Silent spring, pela bióloga naturalista Rachel Carsons, ambas em 1962, potencial izaram as discussões sobre as interações entre ciência, tecnologia e sociedade (CTS). Dessa forma, $C \& T$ passaram a ser objeto de debate político. N esse contexto, emerge 0 denominado movimento CTS.

* Professor do D epartamento de M etodologia do Ensino, Universidade Federal de Santa M aria. Santa M aria, RS. D outorando em Educação pela Universidade Federal de Santa Catarina. Florianópolis, SC (email: decio@ced.ufsc.br).

** Professor Adjunto D outor do D epartamento de Engenharia M ecânica e Coordenador do N úcleo de Pesquisas em Ensino de Engenharia eTecnologia (N epet), U niversidade Federal de Santa Catarina. Florianópolis, SC

(email: wbazzo@emc.ufsc.br). 
Luján Lópes et al. (1996) também destacam os dois aspectos anteriormente apontados como desencadeadores de uma politização sobre ciência e tecnologia. Assinalam a emergência de um questionamento sobre a gestão tecnocrática de assuntos sociais, políticos e econômicos, denunciando as conseqüências negativas da $C \& T$ sobre a sociedade. Esse movimento reivindica um redirecionamento tecnológico, contrapondo-se à idéia de que mais $C \& T$ vão, necessariamente, resolver problemas ambientais, sociais e econômicos. Postula-se a necessidade de outras formas de tecnologia. A alternativa não consiste em "mais $C \& T$ ", mas "num tipo diferente de $C \& T$ ", concebidas com al guma participação da sociedade.

Segundo esses autores, no final da década de 70, esses dois aspectos contribuíram para uma mudança de mentalidade, uma transformação na visão sobre $C \&$ T. H ouve um fenômeno de mudança, em determinadas sociedades, na compreensão do papel da $C \& T$ na vida das pessoas. Essa nova mentalidade/ compreensão da $C \& T$ contribui, na análise dos autores, para a "quebra do belo contrato social para a $C \& T$ ", qual seja, o modelo linear/tradicional de progresso/desenvolvimento. ${ }^{1}$

Passou-se a postular algum controle da sociedade sobre a atividade científico-tecnológica. Um dos objetivos centrais desse movimento consiste em colocar a tomada de decisões em relação à $C \& T$ num outro plano. Reivindicam-se decisões mais democráticas (maior número de atores sociais participando) e menos tecnocráticas.

Em vários países (EUA, Inglaterra, Países Baixos, entre outros) a mudança cultural em curso, a "politização" da C\& T, produziu desdobramentos curriculares nos ensinos superior e secundário.

Em outro trabalho, constituído a partir de uma revisão bibliográfica sobre o movimento CTS, Auler (1998) enfocou o seu surgimento histórico, a tradução dos seus objetivos em novas configurações curriculares, os problemas e as perspectivas encontradas, bem como os desafios que se colocam para o ensino de Ciências (formação de professores) no contexto educacional brasileiro. Entre esses problemas e desafios, situados como possíveis questões de investigação, destacou: formação disciplinar dos professores incompatível com a perspectiva interdisciplinar presente no movimento CTS; compreensão dos professores sobre as interações entre ciência, tecnologia e sociedade; não contemplação do enfoque CTS2 nos exames de seleção; formas e modalidades de implementação; produção de material didático-pedagógico; e redefinição de conteúdos programáticos. C abe destacar que são escassas as publicações sobre a utilização do enfoque CTS no ensino, no contexto brasileiro.

Relativamente a essa revisão bibliográfica, Auler constatou que não há uma compreensão e um discurso consensual quanto aos objetivos, conteúdos, abrangência e modalidades de implementação desse movimento. 0 enfoque CTS abarca desde a idéia de contemplar interações entre ciência, tecnologia e sociedade apenas como fator de motivação no ensino de ciências, até aquelas que postulam, como fator essencial desse enfoque, a compreensão dessas interações, a qual, levada ao extremo por alguns projetos, faz com que o conhecimento científico desempenhe um papel secundário.

\footnotetext{
${ }^{1} \mathrm{DC} \rightarrow \mathrm{DT} \rightarrow \mathrm{DE} \rightarrow \mathrm{DS}$ (modelo linear/tradicional de progresso)

Neste modelo linear, o desenvolvimento científico (DC) gera o desenvolvimento tecnológico (DT); este gera o desenvolvimento econômico (DE) que determina, por sua vez, o desenvolvimento social (DS - bem-estar social). (Luján et al., 1996).

2 É bastante comum encontrar, na literatura especializada, tanto a expressão "movimento CTS" quanto "enfoque CT S". Utilizaremos, neste trabalho, as duas expressões, considerando que o "movimento CTS" busca enfocar as interações entre ciência, tecnologia e sociedade.
} 
Assim, os objetivos apresentados na literatura da área expressam diferentes formas de conceber esse movimento. Promover o interesse dos estudantes em relacionar a ciência com as aplicações tecnológicas e os fenômenos da vida cotidiana, abordar o estudo daqueles fatos e aplicações científicas que tenham uma maior relevância social, abordar as implicações sociais e éticas relacionadas ao uso da ciência e da tecnologia e adquirir uma compreensão da natureza da ciência e do trabalho científico representam uma síntese dos objetivos "mapeados" por C aamaño (1995). Para Rubba e W iesenmayer (1988), a integração entre ciência, tecnologia e sociedade no ensino de ciências representa uma tentativa de formar cidadãos científica e tecnologicamente alfabetizados, capazes de tomar decisões informadas e desenvolver ações responsáveis. 0 utro objetivo que pode ser acrescido ao espectro consiste em alcançar pensamento crítico e independência intelectual (Aikenhead, 1987). Segundo Acevedo Díaz (1996), a idéia de alfabetização em ciência e tecnologia emerge como ideal na denominada "era postsputnik", podendo ser destacado o Projeto 2061, que pretende alfabetizar científica e tecnologicamente todos os cidadãos dos EU A antes que o cometa H alley volte no ano 2061.

\section{C onsiderações sobre 0 contexto brasileiro}

É viável e/ou possível a tradução, em ações educacionais efetivas no contexto brasileiro, dos objetivos anteriormente apresentados? Para essa discussão, no nosso entender, é fundamental considerar que o movimento CTS emergiu, historicamente, em contextos nos quais as condições materiais estavam razoavelmente satisfeitas. Tratou-se, em grande parte, de reivindicaçõ̃es "pós-materiais". ${ }^{3}$ Além disso, em nosso país, a cultura de participação da sociedade em questões nacionais é bastante débil.

$\mathrm{N}$ ão estaria o imaginário de boa parte dos brasileiros, entre os quais professores de ciências, aspirando a um mundo, a um modelo de sociedade, exemplificado pelos chamados países capitalistas centrais? 0 movimento CTS surgiu exatamente nesses países porque uma parte da população começou a questionar esse modelo, essa sociedade. U ma mudança de percepção em relação ao papel da C\&T na vida das pessoas, um dos elementos centrais e motivador desse movimento, já aconteceu em nosso contexto?

Considerando o discurso dos meios de comunicação e de outros segmentos formadores de opinião, não seria meta prioritária de parcela significativa da população a busca do "primeiro mundo"? N ão estaríamos querendo fazer uso das mesmas estratégias em termos de política econômica e tecnológica, esquecendo/ignorando suas conseqüências em termos ambientais, culturais e sociais?

Gana (1995) destaca que a situação social e econômica dos países latino-americanos não é "produto do azar". 0 bedece a uma série de fatores (econômicos, históricos, culturais, políticos, entre outros) internos ao país e externos em suas relações com o resto do mundo. Em nenhum caso essa situação será eliminada ou atenuada exclusivamente pela inovação tecnológica.

\section{Brasil colônia}

M otoyama (1985) discute vários aspectos decorrentes do nosso passado colonial. Para ele, os países do "terceiro mundo", quase todos de passado colonial, não presenciaram um

\footnotetext{
${ }^{3}$ No Brasil, para uma parcela significativa da população, faltam as condições mínimas de sobrevivência.
} 
crescimento científico e tecnológico próprio. Assim, $C \& T$ não estão integradas harmoniosamente nas suas estruturas sócio-econômicas. R eferindo-se a esse passado colonial, destaca que, aparentemente, nos três séculos após o descobrimento do Brasil, praticamente não houve evolução em C\& T. Enquanto os países do centro avançavam de modo marcante, encontrando os seus espaços durante a ascensão do capitalismo, em nosso território, $C \& T$ marcavam passo "sob o implacável jugo da metrópole portuguesa". M otoyama destaca ainda que a eficiência dessa política colonial, traduzida em medidas como a proibição da instalação de oficinas tipográficas ou a apreensão do livro de Antonil sobre as técnicas industriais e de engenho, mereceria um estudo mais aprofundado. Para o autor, essa política deve ter sido muito eficiente, pois passou praticamente despercebida aqui a revolução científica dos séculos XVI e XVII, responsável pela disseminação do espírito científico na Europa, uma das características mais marcantes da chamada modernidade.

Para Sant'Anna (1978), a exploração colonial no Brasil teve sempre um caráter pre datório, sem voltar maiores atenções aos aspectos técnicos, mesmo rudimentares, da atividade econômica. 0 autor ilustra esse aspecto fazendo referência a Fernando de Azevedo:

Se a dinâmica do mundo da técnica traz, nas suas transformações, a fonte de uma constante reconstrução econômica, com as vagas sucessivas de inovações, a economia patriarcal, que entre nós se estabeleceu, tendia a expandir-se, sem se renovar, apoiada como era, na exploração do homem pelo homem, isto é, da energia orgânica, do trabalho servil, utilizado em todas as atividades humanas. (Azevedo apud Sant'Anna, 1978, p.42)

Carvalho e M artins (1998), referindo-se também ao nosso passado colonial, destacam que o modelo agro-exportador da economia brasileira, aliado até 1888 ao regime escravocrata, não favorecia a investigação e o desenvolvimento tecnológico. As exceções que havia ocorriam dentro de uma visão pragmática e imediatista.

M otoyama (1985) reforça que, com a exploração colonial, marcada pela exacerbação da escravidão, por um lado formou-se uma tradição prático-imediatista; por outro a divisão entre atividades manuais e intelectuais contribuiu para conformar uma cultura retóricoliterária. Já o século XIX é caracterizado pela institucionalização da ciência e pela profissionalização do cientista em outros contextos. Os países líderes do capitalismo começam a investir decisivamente em $C \& T$. Contudo, apesar de algumas iniciativas isoladas, como, por exemplo, o programa de saneamento sob a direção de 0 swal do $\mathrm{Cruz}$, a monarquia brasileira estava satisfeita com a sua condição de país primário exportador. D os investimentos em $C \& T$ que ocorriam, muitos não conseguiram escapar aos longos tentáculos do imediatismo ou da cultura retórico-literária, configurada, muitas vezes, no positivismo.

Para Angotti (1991), enquanto na Europa não-ibérica vivia-seum século de “luz" após a reforma e a revolução científica, nas metrópoles ibéricas, mas principalmente nas colônias, vivia-se ainda no século na "escuridão". A ciência entra muito tardiamente no Brasil. O s reflexos da formação de homens "cultos", bacharéis e liberais até hoje impregnam nossa sociedade.

\section{0 processo da industrialização brasileira}

No contexto da chamada substituição das importações, houve o processo de industrialização. Contudo, para M otoyama, seria errôneo imaginar que a investigação científica e 
tecnológica tivesse adquirido uma posição de destaque. A industrialização estava baseada na "importação de tecnologias e de técnicos estrangeiros, movida por propósitos imediatistas", havendo pouca preocupação com a capacitação técnica nacional. 0 autor destaca que 0 insucesso na implementação de políticas científico-tecnológicas, em bases nacionais, adveio muito mais de fatores estruturais inerentes ao subdesenvolvimento do que da má vontade das pessoas envolvidas.

Para o autor, nos dias conturbados da década de 1960, ocorreram alguns eventos de grande importância para o desenvolvimento de $C \& T$ no país: a fundação da U niversidade de Braślia (1961), a concretização da Fundação de Amparo à Pesquisa do Estado de São Paulo (Fapesp), o início do primeiro curso da Coordenação de Programas de Pós-Graduação em Engenharia (Coppe) e a criação do Fundo de D esenvolvimento T écnico-Científico (Funtec) em 1964, no seio do Banco N acional de D esenvolvimento (BN DE). M otoyama salienta que a Funtec nasceu como conseqüência das preocupações dos técnicos do BN DE que - analisando os resultados do Programa de M etas do governo de Juscelino Kubitschek, no qual tiveram papel de destaque - teriam percebido a importância de absorver as inovações tecnológicas para 0 futuro crescimento da economia nacional. Para minorar a dependência, perceberam que seria necessária uma participação mais ativa da empresa nacional no processo de geração e de absorção de tecnologias "forâneas".

$\mathrm{N}$ a segunda metade da década de 60 medidas contraditórias no que se refere à $C \& T$ refletiam as lutas entre as forças realmente interessadas no desenvolvimento científico e tecnológico e as suas oponentes. Assim, a partir de 1967, por intermédio do M inistério das Relações Exteriores, colocou-se em prática a "operação retorno", visando trazer de volta os cientistas brasileiros que estavam trabal hando no estrangeiro. Por isso, foram tomadas várias medidas para melhorar suas condições de trabal ho e remuneração. Contudo,

todas essas boas intenções governamentais eram quase anuladas na prática com as cassações e aposentadorias compulsórias, intensificada no período 1969-1970, com base no Al5, dos cientistas e intel ectuais mais representativos da $\mathrm{N}$ ação. Instalou-se então um clima de desconfiança mútua entre a comunidade científica e as áreas governamentais. (M otoyama, 1985, p.46)

Para C arval ho e M artins (1998), o desfecho trágico da Segunda Guerra M undial fez que o governo incentivasse, por via militar, a pesquisa no campo da energia nuclear. Assim, em 1951, foi criado o Conselho $\mathrm{N}$ acional de Pesquisa (CN Pq), órgão que passou a patrocinar a pesquisa, e que era basicamente voltado ao apoio às investigações em Física Nuclear. Entretanto, para esses autores, pressões do governo americano fizeram o governo brasileiro "optar" pela compra de um reator de urânio enriquecido, em 1969, o que levou à interrupção de trabal hos de investigação. M otoyama também menciona a marginalização da comunidade científica nacional nos acordos nucleares.

Carvalho e M artins (1998) assinalam que, no Brasil, o relacionamento entre o governo e a comunidade científica tem sido freqüentemente difícil. Considerando o episódio dos acordos nucleares, escrevem: "Se a comunidade científica não foi ouvida pelos governos em questões para as quais a opinião dela era essencial, não se poderia esperar que ela o fosse quando se manifestasse sobre questões sociais e políticas" (p.148).

M otoyama (1985) conclui sua análise sobre C\& T no Brasil constatando que elas nunca foram prioridades reais das políticas adotadas ao longo de sua história do país. 0 imediatismo 
e a cultura retórico-literária, aspectos vinculados ao colonialismo, não permitiram um olhar mais profundo sobre a importância da $C \& T$. Em suas palavras, "a ciência foi quase sempre encarada como um ornamento para minorar as misérias culturais brasileiras, enquanto a tecnologia era endeusada como um ente mirífico, poderosa nos seus efeitos, porém impossível de ser obtida por expedientes nacionais" (p.47) [grifo nosso].

Segundo 0 autor, essa visão passa a engendrar efeitos danosos. A maior parte da pesquisa científica é feita visando o reconhecimento externo, buscando, predominantemente, inspirações e motivações na "vitrina estrangeira". U ma segunda conseqüência dessa visão é a desconfiança em relação à pesquisa tecnológica nacional, com desperdício de resultados interessantes de pesquisas. Como conseqüência dos aspectos acima, nem a ciência nem a tecnologia estão harmoniosamente integradas nas instituições sociais, econômicas e culturais brasileiras.

Da mesma forma, Sant'Anna (1978) salienta que, muitas vezes, as sociedades que absorveram tardiamente os princípios da ciência européia contaram com o fator sorte para fazer coincidir os interesses de cientistas europeus e seus próprios interesses. D estaca que a dependência com relação à ciência européia configura-se pelo treinamento do cientista colonial, o qual recebe grande parte ou toda sua formação científica em instituições européias, estuda trabal hos de cientistas europeus, compra livros europeus.

As sociedades dependentes, que buscaram na industrialização uma solução para superar situações de crise econômica, como o Brasil, refizeram em outro plano, segundo Sant'Anna, as relações de dependência mantidas no modelo econômico anterior. Elas buscaram no exterior a tecnologia necessária para a industrialização. Para a obtenção de resultados imediatos (outros autores, anteriormente mencionados, também destacam este aspecto) esse mostrou ser o caminho mais fácil. C ontudo, a perpetuação dessa política estrangulou um desenvolvimento científico e tecnológico autônomo.

José Leite Lopes, físico e pesquisador brasileiro, mencionado por Sant'Anna (1978), manifestando-se sobre o nosso processo de industrialização, destaca que as empresas industriais no Brasil, sendo em sua maioria filiais de firmas e corporações estrangeiras, possuíam seus próprios programas de lucros e investimentos, nem sempre coincidentes com os interesses da $N$ ação. Com isso, a influência de tais empresas, no desenvolvimento da $C \& T$, no Brasil, tem sido praticamente nula.

\section{Ausência de uma política de pesquisa e desenvolvimento}

Sant'Anna (1978), falando em termos genéricos sobre os países em desenvolvimento, destaca que nem sempre o interesse e o empenho em prol da $C \& T$ mostrados pelos governos são motivados pelo bem-estar da população. M uitas vezes, razões de prestígio político e militar internacional direcionam a alocação dos recursos oficiais. Além do mais, na maioria das vezes, os projetos e os planos, tal qual denunciou M otoyama, são calcados nos modelos das chamadas nações avançadas, considerados exemplos dignos de serem imitados.

A autora questiona: que tipo ou modelo de política científico-tecnológica deve ser adotada nos países pobres a fim de acelerar seu desenvolvimento? Conclui que uma resposta significativa somente será dada em função de objetivos prioritários, definidos mediante processos democráticos, de cada sociedade. Alerta que a maior dificuldade nessa decisão não reside na complexidade técnica, mas na natureza conflitiva das estruturas sociais contemporâneas, caracterizadas por interesses e aspirações contraditórios, muitas vezes irreconciliáveis. Para ela, 
compreender o problema do desenvolvimento da $C \& T$ implica a consideração de fatores sociais, econômicos, políticos e culturais.

Para essa autora, parece não haver dúvidas de que o Estado brasileiro tem oscilado entre uma prática política semi-autoritária e autoritária durante a quase totalidade de sua história. Por que então, no Brasil, predominou uma política liberal de laissez-faire na área científica? A resposta deve ser atribuída a um descaso tradicional dos políticos com relação às possíveis contribuições sociais da ciência, atitude legitimada pelo desenvolvimento econômico brasileiro, processado sem vínculos efetivos com a pesquisa do país.

Em Ciência esociedadeno Brasil, Sant'Anna defen de a tese central de que a sociedade brasileira jamais equacionou o problema da $C \& T$ como fator de desenvolvimento, não se estabelecendo, por conseguinte, uma relação dinâmica, recíproca, entre os sistemas produtivo e científico. Em outras palavras, a ausência de uma efetiva vinculação entre ciência e sociedade é característica da história brasileira. Durante décadas, predominou o ponto de vista de que 0 País deveria abrir mão do desenvolvimento tecnológico autônomo, considerando que uma análise do custo-benefício indicava como mais "rentável" a importação de tecnologia. Temos, assim, no Brasil, uma situação circular: 0 tipo de tecnologia adotada pela maioria das empresas faz com que os técnicos necessários para a sua "manipulação, preservação ou adaptação" tenham sua formação limitada a essas linhas de pesquisa, não havendo pesquisadores que pudessem fazer emergir conhecimentos autônomos. Assim, essas empresas ficam presas à tecnologia importada, sem o desenvolvimento de tecnologias alternativas. 0 corre, portanto, a marginalização do setor científico e tecnológico nacional em detrimento da tecnologia importada.

Enfrentamos, na análise de Sant'Anna, dificuldades na definição de uma política científica e tecnológica conectada a uma política industrial,

não somente como conseqüência da incapacidade das instituições definidoras de política científica etecnológica - que selimitam a avaliar cada projeto em termos de seus méritos intrínsecos - mas também pela ausência de correias de transmissão da produção científica e tecnológica ao setor produtivo em função dos laços que este último mantém com o exterior. (Sant'Anna, 1978, p.127) [grifo nosso] ${ }^{4}$

A necessidade de definir e explicitar os objetivos prioritários e de configurar um projeto nacional tem sido postulada por vários autores. Furtado explicita claramente esse dilema, vinculando-0 ao desenvolvimento científico-tecnológico:

Favorecer as tecnologias de ponta pode ser racional se o objetivo estratégico é abrir espaço no mercado externo. $M$ as, se o objetivo principal é alcançar o bem-estar social, não tem fundamento investir em técnicas intensivas de capital e poupadoras de mão-de obra, como se vem fazendo atualmente no Brasil. (Furtado, 1999, p.6)

Como conseguir a participação pública, ação da sociedade na definição de um projeto nacional, se, como afirma H ouaiss e Amaral (1995), o exílio do povo é, dentre todas, a característica mais distintiva de nossa história, da Colônia à República? $\mathrm{Na}$ análise desses autores, sem povo e sem opinião pública, em um país formado predominantemente por negros

${ }_{4}$ Em 16/09/99, no programa Roda Viva da TV Cultura, o presidente da Fapesp fez análise semelhante. Para ele, na década de 90,0 Brasil teve um crescimento significativo em termos de geração de conhecimento. Contudo, esse conhecimento tem ficado muito restrito à área acadêmica, não sendo aplicado/incorporado ao setor produtivo, de tal forma que não gera crescimento e bem-estar social. 
importados/escravizados e índios massacrados, iletrados, fizemos a independência, nos livramos da escravidão negra legal, nos livramos da monarquia e implantamos uma república federativa e presidencialista. $N$ ão há motivos para apostar num processo contemporâneo que subverta o papel tradicional dos atores de nosso processo político clássico. Pelo contrário, para os autores, "a história contemporânea fortalece os pactos de elites - e o exílio histórico do povo". Ainda nessa análise, "o autoritarismo tem sido a regra, a ditadura, a norma; a exceção é a 'democracia'. E que democracia? A estranha democracia de massas sem povo". H istoricamente, somos uma sociedade onde predominou o latifúndio, a monocultura, o escravismo. Concluem:

U ma das fontes de nossa tragédia é o fato de que jamais tivemos um projeto nacional. $\mathrm{N}$ ão apenas no sentido de não havermos tido uma revolução nacional, na acepção marxista, mas também no sentido de que a burguesia brasileira jamais se confundiu com os interesses do país, sua sobrevivência jamais dependeu de um projeto nacional. (H ouaiss \& Amaral, 1995, p.119)

Também Sant'Anna destaca que, na passagem do modelo agrário-exportador à tentativa de industrialização, ou seja, após a crise da oligarquia agrária, não tivemos, nesse processo de transformação em curso no Brasil, projetos formulados pela burguesia que fossem compatíveis com a idéia do aproveitamento e da indução do processo de desenvolvimento do sistema científico-tecnológico. 0 u seja, houve limitações da burguesia industrial em relação à liderança do processo de desenvolvimento nacional. Essa nossa análise não significa um julgamento de valor quanto à presença atuante ou não da "burguesia nacional". Q uer indicar que o nosso processo histórico foi muito diferenciado em relação ao dos países centrais onde emergiu o movimento CTS.

Gana (1995), por sua vez, anal isa o comportamento das classes dominantes na América Latina. Em geral, elas não apresentavam vinculação local. Estavam mais ligadas ao mercado estrangeiro do que à própria região. 0 s donos das terras, os mineradores e os mercadores cumpriam a função de abastecer a Europa de ouro, prata e alimentos. Essa burguesia era muito diferente da empreendedora burguesia européia ou norte-americana. "As burguesias latinoamericanas nasceram como simples instrumento do capitalismo internacional, prósperas peças da engrenagem mundial."

A revista Ciência H oje, editada pela Sociedade Brasileira para o Progresso da Ciência (SBPC), também tem, freqüentemente, postulado a necessidade de um projeto nacional de desenvolvimento. N esse sentido, a fala reproduzida a seguir é exemplar: "Entre nós, muito ainda resta a fazer até que seja reconhecido, em toda a sua plenitude, o papel fundamental e insubstituível da ciência e da tecnologia em um verdadeiro projeto de desenvolvimento nacional" (Ciência H oje, mar. 1995, p.1).

Para Sachs (1996), o desafio para o Brasil, como para todos os países que aspiram a um autêntico desenvolvimento, é fazer coincidir, tanto quanto possível, o progresso científico e tecnológico com o progresso social. As finalidades do desenvolvimento devem ser definidas a partir de critérios éticos e sociais. Em suas palavras,

isso nos leva ao que parece ser a principal fraqueza do sistema de pesquisa brasileiro: a ausência de respostas claras para as perguntas: quais as prioridades de pesquisa, quais as tecnologias, para qual desenvolvimento? $\mathrm{Na}$ realidade, deve se começar a 
responder à última dessas perguntas. Sem um projeto nacional que defina as grandes linhas de uma estratégia de longo prazo, será difícil, ou até impossivel, responder às duas primeiras. 0 país não pode se furtar a um amplo debate público a esse respeito. (Sachs, 1996, p.13)

\section{0 momento presente}

Para Gana (1995), as características do mercado mundial e a competição internacional obrigam os países menos desenvolvidos a se adaptarem às tendências impostas pelo mercado. Com isso, a modernização tecnológica da indústria da América Latina obedece, muitas vezes, a pressões do exterior, não sendo necessariamente uma conseqüência lógica do nível de desenvolvimento local nem do ritmo alcançado pelas forças produtivas desses países. Em outras palavras, nos países periféricos o progresso técnico só atinge determinados setores da população, geralmente não penetrando senão onde se faz necessário para produzir alimentos e matérias-primas de baixo custo com destino aos grandes centros industriais.

Com relação ao Brasil, evidenciando a ausência de um projeto nacional, bem como a continuidade do processo de importação tecnológica, Luiz $\mathrm{M}$ artins de $\mathrm{M}$ el $0^{5}$, através da análise dos recentes incentivos fiscais dados à G eneral $M$ otors ( $G M$ ), no Rio G rande do Sul, e à Ford, na Bahia, destacou dois aspectos rel evantes: a) em países capitalistas centrais, como nos EUA, há leis que proíbem a concessão de incentivos fiscais a empresas que não sejam nacionais; b) a execução dessa política não propicia a absorção ou transferência de conhecimento: "elas apenas fazem engenharia adaptativa".

D a mesma forma, Ferreira, então presidente da SBPC, destaca:

A grande dúvida hoje é qual papel cabe aos países do Tercei ro M undo no processo de globalização - se o de mero consumi dor ou o de produtor de conhecimento científico e tecnológico. A resposta não etá clara para nós, mas para os formuladores da globalização ela está definida: cabe a nós sermos apenas um bom mercado consumidor estável. 0 resto, deixem que o mundo produza. ... N ós só tivemos um crescimento consentido, em que, no fundo, sempre fomos consumidores (Ferreira, 1998, p.10)

Cano, economista, professor da U nicamp e ex-integrante da Comissão Econômica para a América Latina (C epal), ao analisar a formação do M ercosul e a possibilidade de constituição da Associação de Livre Comércio das Américas (Alca), comenta:

Essa proposta de rearranjo do mundo, com a abertura das economias para as grandes empresas, só permitirá a entrada de ciência e tecnologia no Brasil embutida nos produtos $\mathrm{N}$ ão podemos nos iludir achando que haverá transferência de conhecimentos tecnológicos. D a partedo governo, o raciocínio parece ser o seguinte: 'Para que manter ciência? Para satisfazer o ego de meia dúzia de cientistas nacionais? Besteira! M elhor economizar'. 0 pior é que muitos cientistas brasileiros, encastelados, não se dão conta disso. (C ano, 1999, p.9) [grifo nosso]

\footnotetext{
5 M ELO , L. M . "O papel do financiamento público e privado no desenvolvimento científico e tecnológico" (51ā Reunião Anual da SBPC - Porto Alegre, RS). Painel, 1999.
} 
Na opinião de Vaccarezza (1998), a política científica e tecnológica, na América Latina, no contexto da denominada globalização, limita-se a promover a competitividade internacional das unidades produtivas. $0 \mathrm{~s}$ atores principais passam a ser as empresas. 0 Estado, potencial formulador de políticas, tem ficado num segundo plano, estando sua ação restrita ao estimulo à inovação, fundamental para esta competitividade. D estaca que o critério de competitividade internacional, contudo, pode ser útil a um setor privilegiado da economia, ficando, num segundo plano, a demanda interna, as reais necessidades da sociedade latino-americana.

\section{A influência dos meios de comunicação}

Angotti (1991) destaca que, no Brasil "moderno", as pessoas assistem à TV, acionam botões e interruptores sem que tenham acesso aos conhecimentos fundamentais que embasam essas produções humanas. Além disso, não têm um conhecimento crítico que "possa nortear seletividades e posicionamentos frente à parafernália tecnológica ao longo de sua existência". Para ele,

o dado a ser considerado é o acesso marginal que a população tem aos resultados da Ciência Aplicada, controlados pelos processos tecnológicos e pela política econômica. Assim, há de fato uma participação, confusa ealienada, das pessoas, na "modernidade brasileira". M odernidade que coleciona lancesinfelizes, como o "acidente de G oiânia", a devastação de florestas, a propaganda irresponsável de remédios milagrosos nas emis soras de rádio e o debate barulhento sobre os destinos do Proálcool e o uso de M etanol. M odernidade falsa que não instrumentaliza o cidadão a participar, a alterá-la, a transformá-la. Falta de educação! Falta de educação em C\& T. (Angotti, 1991, p.9)

O s meios de comunicação têm tido um papel significativo enquanto formadores de opinião, especialmente sobre as interações entre ciência, tecnologia e sociedade. Além dos aspectos apontados por Angotti, que mensagens estariam explícitas ou implícitas em jornais, revistas etc?

$\mathrm{Na}$ capa do jornal Zero H ora de 29/08/99, aparece em destaque: "O alfabeto do futuro: a internet estabelece 0 ritmo do progresso, impõe sua presença em todas as dimensões da vida e se converte em condutora dos rumos da civilização". Segundo este discurso no qual a internet "estabelece o ritmo do progresso" e "se converte em condutora dos rumos da civilização", a ação humana desaparece. Sob a lógica dessa concepção, sobra alguma possibilidade para o direcionamento da sociedade sobre $C \& T$ ?

Em muitas das mensagens veiculadas, o desenvolvimento científico-tecnológico é apresentado como irreversível. Tal qual no modelo linear/tradicional de progresso, anteriormente mencionado, os desenvolvimentos científico-tecnológicos são apresentados como inexoráveis, representando a marcha do progresso.

Se o processo é inexorável, exclui a possibilidade de alterar o ritmo das coisas. A participação da sociedade em nada alteraria o curso do processo em andamento. N esse modelo linear está presente a idéia da inevitabilidade do processo e do progresso, alijando a sociedade da participação em decisões que envolvem seu destino. Ignora-se um aspecto apontado por Fourez (1995), ou seja, de que ao adotar determinada tecnologia, estamos adotando determinado modelo de sociedade. D estacamos alguns artigos/falas que são elucidativos quanto à propagação dessa concepção. 
0 artigo "Tem comida estranha na geladeira", publicado pela revista Epoca em março de 1999, ilustra, de forma exemplar, o aspecto anteriormente mencionado. Trata-se de um artigo sobre a utilização de al imentos transgênicos na alimentação. M esmo admitindo que há questões ambientais, éticas e religiosas envolvidas, inicia o artigo desta forma: "A onda é irreverśvel. Por mais forte que seja a desconfiança em relação aos produtos geneticamente modificados, não há mais como fugir deles" (p.56).

Segundo o mesmo artigo, existe uma remota possibilidade de a comercial ização não ser autorizada:

Se a comercialização for autorizada, como tudo indica, as primeiras colheitas de soja transgênica ocorrerão em abril do ano 2000. N a contramão, ambientalis tas, consumidores, o ministro do M eio Ambiente, José Sarney Filho, e a Sociedade Brasileira para o Progresso da Ciência (SBPC) defendem uma moratória até que despontem conclusões científicas inquestionáveis. (p.58-9)[grifo nosso]

Além da clara tentativa de direcionar a opinião dos leitores, utilizando expressões como as grifadas, o artigo utiliza a expressão "conclusões científicas inquestionáveis". U ma idéia altamente pretensiosa, pois, por maior que seja o número de resultados de laboratório, considerando a complexidade da biodiversidade, problemas poderão aparecer a médio ou longo prazo. Além disso, já tendo sido descartados aspectos éticos, religiosos e outros, somente aspectos técnico-científicos poderão deter o processo de implantação. O u seja, a decisão final será tecnocrática.D a mesma forma, colocando a introdução de produtos transgênicos como um imperativo, algo inevitável, aparece 0 artigo "M eu gene, meu bem, meu mal", da revista Superinteressante de maio de 1999, que introduz o artigo de forma sugestiva: "O Brasil vai produzir vegetais geneticamente modificados. Isso coloca o país no centro do bate-boca mundial em torno da segurança dos alimentos transgênicos para a saúde e o ambiente" (p.51) [grifo nosso] destacado:

$\mathrm{Na}$ introdução do mesmo artigo, acentuando a inevitabilidade do processo, é

Você entra no supermercado, pega uma espiga de milho e sabe que etá comprando um produto criado pela natureza. Com um tanto de agrotóxico, é verdade, mas, ainda assim, natural. Pois, daqui a algum tempo, na mesma prateleira, vocêvai dar de cara com o milho transgênico. (p.52) [grifo nosso].

G ana (1995) salienta que a idéia de progresso contínuo, evolutivo e linear, segundo o qual a humanidade avança de níveis inferiores a superiores não é, provavelmente, um conceito que tenha surgido autonomamente em regiões do terceiro mundo, mas uma doutrina que tem sido tomada como corpo conceitual do ocidente. Para ela, especialmente no século XIX e início do XX, a conexão entre ciência, tecnologia e indústria foi a base do discurso que vincula tecnologia e progresso, um processo considerado determinístico, inevitável e que, até certo ponto, "todos os cidadãos do ocidente carregam fragmentos desta concepção em sua linguagem e atitudes".

Para Buarque (1990), é surpreendente a rapidez como a idéia de progresso, a partir da revolução industrial, consolidou-se como um "valor intrínseco, impregnado à imaginação dos homens, em todos os continentes, praticamente em todos os povos". Segundo ele, "surpre ende como adquiriu primazia sobre todas as demais idéias socialmente aceitas, a ponto que as 
outras, como felicidade, paz, igualdade, liberdade, justiça, soberania, embora mais antigas, passaram a ser vistas como conseqüência do progresso" (p.48).

\section{Considerações finais}

Temos aspectos peculiares ao contexto brasileiro, decorrentes, em grande parte, do nosso passado colonial e da nossa posição nas relações econômicas internacionais. A longa vigência do modelo agrário-exportador contribuiu para a configuração de um pragmatismo/imediatismo, bem como para uma cultura retórico-literária. Além disso, no contexto da industrialização, a importação/transferência de tecnologia, sem a respectiva transferência de conhecimentos, inviabilizou o desenvolvimento científico-tecnológico nacional. Tanto no modelo agro-exportador quanto no da industrial ização, a análise realizada remete à ausência de um projeto de nação. Como conseqüência, não há uma articulação dinâmica entre ciência, tecnologia e sociedade. Também, em nossa história, convivemos com um Estado predominantemente autoritário, no qual, geralmente, o povo brasileiro está alijado de qualquer participação.

Sem postular um determinismo histórico, porém admitindo que os condicionamentos históricos devem ter deixado marcas no pensar dos professores brasileiros, a pretensão de implementar o movimento/enfoque CTS no contexto educacional brasileiro coloca questões como: qual a compreensão dos professores de Ciências sobre as interações entre ciência, tecnologia e sociedade? Q uais são suas crenças, suas concepções de progresso? 0 s professores associam linearmente progresso com inovações tecnológicas, supostamente neutras? 0 processo histórico vivenciado não teria contribuído para que parcela significativa dos professores endossem uma perspectiva tecnocrática, concepção que inviabiliza o movimento CT S? Essas são questões que, no nosso entender, carecem de um aprofundamento teórico e empírico para uma efetiva implementação do enfoque CTS no contexto brasileiro.

H istoricamente, sob o domínio de um Estado autoritário, num país sem histórica de participação, é plausível postular al gum controle da sociedade sobre $C \&$ T ? Além disso, corremos o risco, conforme salienta Santos (1997), de educar as pessoas para uma falsa cidadania, considerando que, nos contextos em que emerge o movimento CTS, há mecanismos de consulta popular, já estabelecidos, para avaliar e influir nas decisões relativas à C\&T, inexistentes em nosso contexto.

Ao assumirmos criticamente os objetivos do movimento CTS, há indicativos de que, além de conhecimentos/informações, necessários para uma participação mais qualificada da sociedade, necessitamos, também, iniciar a construção de uma cultura de participação.

\section{Referências bibliográficas:}

ACEVED O DÍAZ, J. A. La tecnología em las relaciones CTS: una aproximación al tema. Enseñanza de las Ciencias, v.14, n.1, p.35-44, 1996.

AIKEN HEAD, G.S. High-school graduates beliefs about science-technology-society: The characteristics and limitations of scientific knowledge. Science Education, v.71, n.2, p.45987, 1987.

AN GOTTI, J. A. Fragmentos e totalidades no conhecimento científico e no ensino de ciências. Tese (D outorado em Educação). Faculdade de Educação, Universidade de São Paulo, São Paulo, 1991. 
AULER, D. M ovimento Ciência-Tecnologia-Sociedade (CTS): modalidades, problemas e perspectivas em sua Implementação no ensino de física. In: Encontro de Pesquisa em Ensino de Física, 6, Resumos..., Florianópolis, 1998.

BAZZO, W. A. Ciência, Tecnologia e Soci edade e o contexto da educação tecnológica. Florianópolis: UFSC, 1998.

BU ARQ UE, C. A desordem do progresso: o fim da era dos economistas e a construção do futuro. Rio de Janeiro: Paz eTerra, 1990.

CAAM AÑ O A. La Educación Ciencia-Tecnologia-Sociedad: una necesidad en el diseño del nuevo curriculum de ciencias. Alambique: didáctica de las $\mathrm{Ciencias} \mathrm{Experimentales.}$

Barcelona, año II, n.3, p.4-6, Enero, 1995.

CAN O , W. M ercosul, integração ou diferenças? Ciência H oje, Rio de Janeiro, v.26, n.151, p.6-9, jul. 1999.

CARVALH O, W. L. P.; M ARTIN S, J. Elementos H istóricos: Ciência-Sociedade-Governo no Brasil. In: N ARDI, R. (O rg.) Pesqui sas em Ensino de Física. São Paulo: Escrituras

Editora, Série Educação para a Ciência, n.1, 1998, p.139-152.

EDITORIAL. Ciência Hoje, Rio de Janeiro, mar. 1995.

FERREIRA, S. H. Entrevista. Ciência H oje, Rio de Janeiro, v.24, n.140, p.8-11, jul. 1998.

FO UREZ, G. A construção das Ciências: Introdução à filosofia e à ética das ciências. São

Paulo: EDUNESP, 1995.

FU RTAD 0 , C. A reconstrução do Brasil. Folha de São Paulo, seção 2-6, 13 jun. 1999.

GAN A, M. T. S. Reflexiones en torno a la tecnología: su diagnostico en la periferia. Tesis

(D octorado en lógica y filosofia). Facultat de Filosofia y Psicología, D epartamento de Lógica y Filosofía, U niversidad de Valencia, 1995.

H OUAISS, A. e AM ARAL, R. A modernidade no Brasil: conciliação ou ruptura? Petrópolis: Vozes, 1995.

IGLESIA, P. M. Una revisión del movimiento educativo Ciencia-Tecnología-Sociedad.

Enseñanza de las Ciencias. Barcelona, v.15, n.1, p.51-57, 1997.

LUJÁN LÓ PES, J. L. et al. Ciencia, Tecnología y Sociedad: una introducción al estudio social de la ciencia y la tecnología. M adrid: TECN OS, 1996.

"M eu gene, meu bem, meu mal". Superinteressante, São Paulo, p.51-55, mai. 1999.

M OTOYAM A, S. O s principais marcos históricos em ciência e tecnologia no Brasil.

Sociedade Brasileira de História da Ciência, São Paulo, n.1, p.41-49, jan.-jun. 1985.

RUBBA, P. A. e W IESEN M AYER, R. L. Goals and competencies for precollege ST S education: recommendations based upon recent literature in environmental education. Journal of Environmental Education, n.19, v.4, p.38-44, 1988.

SACHS, I. Brasil e os riscos da modernidade. Ciência H oje. Rio de Janeiro, v.20, n.119, p.12-14, abr. 1996.

SAN T 'AN N A, V. M . Ciência e Sociedade no Brasil. São Paulo: Símbolo, 1978.

SANTOS, W. L. P. 0 Ensino de química para formar o cidadão: principais características e condições para a sua implantação na escola secundária brasileira. D issertação (M estrado em Educação). Faculdade de Educação, U niversidade Estadual de Campinas, C ampinas, 1992. "Tem comida estranha na geladeira". Época, São Paulo, p.56-61, 01 mar. 1999.

VACCAREZZA, L. S. Ciência, Tecnología y Sociedad: el estado de la cuestión en América Latina. Revista Iberoamericana de Educación, n.18, p.1-22, setembro-dezembro, 1998. 
